\title{
Van typiste naar ingenieur?
}

\section{Inzichten uit vijftig jaar representaties van gender en beroep in NT2-tekstboeken (1974-2017)}

\author{
Dietha Koster en Chiara Iding \\ Westfälische Wilhelms-Universität Münster
}

Studies on English language learning materials indicate that women are underrepresented and often appear in low-status professions, though gender equality increases within the last decade (Sunderland, 2015). To what degree does this finding apply for textbooks for learners of Dutch as a Second Language (DSL)? To our knowledge, there are no studies into gender and profession in DSL materials. Dutch however, constitutes an interesting case as both female, male and 'gender neutral' professional role nouns exist, while their use is not formally regulated. We systematically analyzed textual and pictorial representations of female and male professionals in textbook chapters about work in fifteen DSL textbooks published within the last 50 years. We drew on quantitative (e.g., number of fe/male and 'gender neutral' professional names; instances of male generics and firstness; number of depicted wo/ men) and qualitative (e.g., nature of the most frequent professional names; categorization of textbook images) methods to do so. Results show that women are not underrepresented in dialogues and pictures, but that dialogue themes are unequally divided over women and men. Moreover, women are backgrounded through male generics and male firstness and female professional names appear less frequently than male names. Women are also described in gender typical roles, whereas men are not. This holds for both older (1974-2009) and recent textbooks (2011-2017). Overall, more 'gender neutral' nouns refer to men in the corpus, but they are used more frequently to refer to women within the last decade. Future studies should address the present theme from psycholinguistic and classroom discourse perspectives and consider additional analytical domains (e.g. chapters about family) and foci (e.g. analyses of verbs associated with wo/men). We discuss pedagogical implications (e.g., screen materials for male firstness; describe women in a greater variety of roles; reverse gender roles in class) for those with concern for gender equality in language education.

Keywords: gender, professional names, learning materials, L2 Dutch, corpus linguistics 


\section{Introductie}

In contrast met internationaal onderzoek naar gender in leerboeken (Risager, 2018), is literatuur over tekstboeken Nederlands als tweede taal (NT2) vanuit een genderperspectief ontraceerbaar. ${ }^{1}$ Het gebrek aan onderzoek komt wellicht niet als verrassing, omdat $\mathrm{NT}_{2}$ een relatief jong professioneel veld is. Aan de andere kant is NT2-onderwijs in Nederland, België of elders in de wereld uitgegroeid tot een gevestigde industrie (Bossers e.a., 2015). De hoeveelheid NT2-leermateriaal is over de jaren heen toegenomen, maar onze kennis over de representatie van vrouwen en mannen in zulk materiaal niet. Dit is onwenselijk, omdat duizenden NT2-leerders door onderwijsmateriaal een 'verborgen curriculum' meekrijgen, wat hen een potentieel beperkend genderbeeld voorspiegelt (Stromquist, Lee, \& Brock-Utne, 1998; Menard-Warwick, Mori, \& Williams, 2017). Dit kennisgebrek vraagt om empirisch werk wat genderrepresentaties in $\mathrm{NT} 2$-tekstboeken op de onderzoekagenda zet. Zulke kennis is niet alleen relevant voor taal- en genderonderzoek(st)ers, maar ook voor NT2-docentes en docenten, -studenten en -studentes, schrijfsters, schrijvers, uitgevers en uitgeefsters van $\mathrm{NT}_{2}$-onderwijsmateriaal. ${ }^{2}$

Met name materiaal voor onderwijs Engels als tweede taal is grondig onderzocht na de feministische revoluties omstreeks 1970 (Lakoff, 1973; Sunderland, 1994, 2010, 2015; Mustapha \& Mills, 2015). Wat blijkt uit dit onderzoek is dat in materiaal gepubliceerd na 1970 tot recentelijk, uitzonderingen daargelaten, vrouwen systematisch minder zichtbaar zijn dan mannen (Sunderland, 2015). Dit blijkt bijvoorbeeld uit het vaker voorkomen van mannen dan vrouwen op afbeeldingen in leermateriaal (Jiménez Catalán, \& Ojeda Alba, 2001). Of uit het voorkomen van male generics, mannelijke generieke vormen (bijv. De ingenieur moet zijn beslissing maken) en male firstness (bijv. Piet en Anna) (Sunderland, 2015).

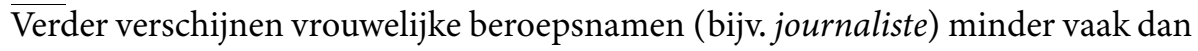
mannelijke (bijv. timmerman) of generieke (bijv. ingenieur) beroepsnamen en vrouwen worden vaker in beroepen met lage status weergegeven (Bengoechea \& Simón, 2010; Gouvias \& Alexopoulos, 2018).

Het beroepsdomein is belangrijk om te onderzoeken, omdat betaald werk is verbonden met sociale status, financiële zelfstandigheid en (zelf)beschikking.

1. In het volgende hanteren we de term NT2 om zowel naar de NT2- als NVT-context te verwijzen. We beschouwen gender als een sociale constructie, die niet vaststaat maar wordt uitgevoerd (Butler, 1990).

2. De gender strategie in dit paper is beide geslachten zichtbaar te maken door zowel mannelijke als vrouwelijke (beroeps)namen te hanteren, waarbij we erop letten dat vrouwen en mannen ongeveer even vaak als eerste worden genoemd. 
Demografische cijfers bieden een referentiekader voor de beroepsmatige 'genderrealiteit' in Nederland. Het Centraal Bureau voor de Statistiek (CBS, 2017) toonde dat in 1969 in Nederland 1,5 miljoen vrouwen (35,1\% van alle vrouwen) werkzaam waren, maar dat dit aantal in 2016 op 4,2 miljoen (65,1\% van alle vrouwen) lag. Onder mannen daalde de bruto-arbeidsparticipatie sinds 1969 van 85,2 naar $74,9 \%$ in 2016. Alhoewel vrouwen en mannen in meer gelijke getalen deelnemen aan het beroepsleven, zijn sommige professionele domeinen nog steeds exclusief vrouwelijk of mannelijk (CBS, 2010). Verzorgende beroepen als zuster, secretaresse en stewardess worden bijvoorbeeld bijna exclusief uitgeoefend door vrouwen, terwijl technische beroepen, zoals bouwvakker, timmerman of stratenmaker bijna exclusief door mannen worden uitgeoefend (CBS, 2005).

Het doel van dit paper is te onderzoeken hoe vrouwen en mannen worden gerepresenteerd in hoofdstukken over werk in NT2-tekstboeken uit de afgelopen 50 jaar. De algemene hypothese, sterk gebaseerd op genderstudies naar leerboeken Engels, is dat ook voor NT2-materiaal uit de periode 1970-nu onderrepresentatie van vrouwen vast te stellen valt. We voorspellen echter dat deze minder zichtbaar is in onderwijsmateriaal verschenen in de laatste twintig jaar, doordat gendergelijkheid in deze periode steeds prominenter op de publieke agenda is komen te staan (Gerritsen, 2002; Sunderland, 2014; Vermeulen, 2018). We onderzoeken genderrepresentaties door een systematische analyse van vijf genderaspecten in hoofdstukken over werk uit vijftien NT2-methodes. Deze punten behelzen zowel talige als visuele genderaspecten (zie Sectie 3.2.). Door in kaart te brengen hoe gender wordt weergegeven in NT2-leermateriaal ontstaat bewustzijn over potentiële genderongelijkheid. Een streven naar inclusief talenonderwijs, waarin leermiddelen diversiteit in (gender)representaties van mensen tonen, is de aanleiding van deze studie.

\section{Theoretisch kader}

Mustapha en Mills (2015) onderscheiden drie fasen in (internationaal) onderzoek naar gender en materiaal voor talenonderwijs. Onderzoek in de eerste fase (die startte omstreeks 1970) had tot doel bewustzijn te creëren van genderongelijkheid door taal en beeld in tekstboeken te analyseren (Schmitz, 1975; Sunderland, 1994). Beroepsnamen vormen hier een belangrijke focus voor verschillende talen waaronder Spaans (Bengoechea \& Simón, 2010) en Grieks (Gouvias \& Alexopoulos, 2018). In de tweede fase werd bekeken of leermaterialen worden aangepast aan de hand van eerdere bevindingen (zie Lee \& Collins, 2009, 2015). In de derde fase wordt door discoursanalyse onderzocht hoe docenten in hun onderwijs omgaan met tekstboekteksten waarin gender een rol speelt, oftewel teksten over mensen 
(Sunderland, Cowley, Fauziah, Leontzakou, \& Shattuck, 2001; Pawelczyk \& Pakula, 2015). De focus van dit paper valt te plaatsen binnen de eerste en tweede fase van bewustwording over genderrepresentaties in NT2-onderwijsmateriaal (een project wat past in derde fase is in voorbereiding, Koster \& Litosseliti).

Sunderland (2015) bespreekt welke genderaspecten in tekstboeken onderzocht (kunnen) worden. Wegens beperkte ruimte bespreken we alleen aspecten die wij selecteerden voor het huidige onderzoek. Beeldanalyses richten zich op afbeeldingen in tekstboeken (zie Giaschi, 2000; Van Leeuwen, 2008; Mustapha, 2015; Kuipers, Van der Laan, \& Arfini, 2017). Een oud, maar relevant model hiervoor werd voorgesteld door Schmitz (1975). Zij stelde voor afbeeldingen te categoriseren in de categorieën onderschikking (het exclusief afbeelden van vrouwen in beroepen met lage status); exclusie (het uitsluiten van vrouwen op afbeeldingen) en degradatie (neerbuigende beelden van vrouwen). Jiménez Catalán en Ojeda Alba (2001) analyseerden 815 afbeeldingen volgens dit model in een Engels-Spaans beeldwoordenboek (Summers, 1992). Degradatie werd niet bevestigd, alhoewel de onderzoeksters stellen dat sommige tendensen in de afbeelding van vrouwen wel als degraderend aangemerkt kunnen worden. Ze vonden onderschikking omdat alleen mannen werden afgebeeld als advocaat, president, wetenschapper, architect of dokter, terwijl zuster, model, filmster, zangeres of waarzegster exclusief vrouwelijke beroepen waren. Tot slot bevestigden ze exclusie, daar ze 225 beelden van mannen vonden tegenover 74 van vrouwen. Wij onderzoeken in hoeverre een analyse van afbeeldingen in $\mathrm{NT}_{2}$-materiaal de categorieën bevestigd.

Veel talige analyses hebben gefocust op de frequentie en aard van mannelijke, vrouwelijke en 'genderneutrale' beroepsnamen. Bengoechéa en Simon (2010) vonden bijvoorbeeld in een analyse van 60 leerboeken Spaans dat vrouwelijke beroepsnamen significant minder vaak werden genoemd dan mannelijke, zelfs in recente boeken (31 tekstboeken gepubliceerd na 2004). Andere analyses focusten op het verschijnen van mannelijke generieken en male firstness (Sunderland, 2015). Er is ook onderzocht hoeveel vrouwen en mannen deelnemen aan dialogen in tekstboeken, wie meer aan het woord is en met betrekking tot welke thema's (Jones, Kitetu, \& Sunderland, 1997; Pawelczyk \& Pakula, 2015). Lee en Collins (2009) toonden bijvoorbeeld aan dat in leerboeken Engels, mannen in dialogen vooral worden geassocieerd met de thema's criminaliteit, politiek, nationale identiteit en succes; en vrouwen met vriendschap, ziekte en uiterlijk. Wij onderzoeken in hoeverre deze bevindingen in een analyse van taal in NT2-tekstboeken worden weerspiegeld.

In het Nederlands zijn zowel mannelijke, vrouwelijke als 'genderneutrale' beroepsnamen gangbaar (zie Gerritsen, 2002). In 1975 wees Romein-Verschoor al twee talige problemen voor deze situatie aan die nog steeds spelen (Vermeulen, 2018). Dit betreft het refereren naar vrouwen met 'genderneutrale' termen, die 
een mannelijke geschiedenis hebben (bijv. psychiater) en het ontbreken van genderspecifieke beroepsnamen voor bepaalde beroepen (bijv. timmerman versus ${ }^{\star}$ timmervrouw). In beide gevallen worden vrouwen onzichtbaar geacht. Na de aanname van de Wet Gelijke Behandeling Vrouwen en Mannen (1981) woedden verhitte debatten over neutraliseren versus differentiëren. In 2001 publiceerde de Taalunie een gids met de mogelijkheden (De Caluwe \& Van Santen, 2001), zodat mensen hun eigen keuze kunnen maken (voor personeelsadvertenties is het wel wettelijk verplicht dat expliciet naar beide geslachten wordt verwezen). Deze onduidelijke situatie is sindsdien onveranderd, maar in het huidige publieke debat valt een voorkeur voor 'genderneutrale' naamwoorden te constateren (Peters, 2016; Bolle, 2017; Vermeulen, 2018). Door gebrek aan regelgeving en onderzoek omtrent gender en beroepsnamen, bestaat echter geen consensus over wat een 'genderneutraal' naamwoord is.

Psycholinguïstisch onderzoek biedt inzicht in hoeverre Nederlandstaligen beroepsnamen met (succes van) vrouwen en mannen associëren. De Backer en De Cuypere (2012) hebben een van de weinige onderzoeken uitgevoerd naar (historisch mannelijke) generieken voor het Belgisch-Nederlands. Ze vonden dat generieken inderdaad meer genderflexibel worden geïnterpreteerd dan in een taal als het Duits, waar generieken in de regel worden geassocieerd met mannen (Stahlberg, Sczesny, \& Braun, 2001). Echter, de genderflexibele interpretatie is sterker voor non-professionele termen (bijv. reiziger) dan voor beroepsnamen. Vervecken, Hannover en Wolter (2013) onderzochten in hoeverre Nederlandssprekende kinderen gevoelig zijn voor het (niet-)markeren van gender op beroepsnamen. Kinderen werden geconfronteerd met (historisch mannelijke) generieken (bijv. psychiater) versus paarvormen met mannelijke en vrouwelijke woorden (bijv. advocate-advocaat). Vervolgens werden ze gevraagd succes van vrouwen en mannen ("Wie is er succesvol?") op een vijfpunt Likert schaal te beoordelen. Vrouwen werden als minder succesvol beoordeeld in de generieke conditie dan in de paarvorm-conditie (Vervecken e.a., 2013; Vervecken, Gygax, Gabriel, Guillod, \& Hannover, 2015). Vanuit een gendergelijkheidsperspectief bestaat dus de voorkeur voor een grotere zichtbaarheid van vrouwen door het gebruik van vrouwelijke beroepsnamen. 


\section{Methode}

\subsection{Corpus}

We selecteerden vijftien NT2-boeken uit de periode 1974-2017 (zie Appendix). Dit brede tijdvak werd opgedeeld in vijf periodes: 1974-1979; 1980-1989; 1990-1999; 2000-2009; en 2010-2017. Voor elk tijdvak werden drie NT2-methodes geanalyseerd (bijv. Actief Nederlands, 1976; Delftse methode, 1985; Code Nederlands, 1990; Contact!, 2009; Taal totaal, 2017). Selectiecriteria waren dat de methode A. een hoofdstuk over werk en beroep bevatte en B. alle deelvaardigheden trainde (lezen, luisteren, schrijven, spreken). Voor vijf boeken vanaf 2000 werd het Europees Referentiekader (ERK)-niveau aangegeven. Deze boeken waren bestemd voor niveau $\mathrm{A}_{1}, \mathrm{~A}_{2}$ en $\mathrm{B}_{1}$. Negen boeken zijn gepubliceerd in Nederland, twee in België, twee in Duitsland, één in Engeland en één in zowel Nederland als België. Al met al bevatte ons corpus stukken tekst over werk en beroep, soms verdeeld over een werk- en oefenboek, uit vijftien NT2-methodes, die opgeteld 13070 types (unieke woorden) en 56918 tokens (alle woorden, inclusief herhaalde types) bevatten.

\subsection{Analyse}

\subsubsection{Type-token analyse van beroepsnamen}

Uit deze analyse blijkt of mannen talig zichtbaarder zijn dan vrouwen in NT2-lesmateriaal over werk. Voor ieder hoofdstuk werd het totale aantal types en tokens berekend met AntConc software (Anthony, 2018). We telden handmatig mannelijke, vrouwelijke en 'genderneutrale' beroepsnamen (types) en hanteerden hierbij een brede definitie van beroep als 'een bezigheid waarmee men de kost verdient'. We telden ook tokens die we hier specificeerden als een (voor)naamwoord wat naar de type verwijst. Deze werden geclassificeerd als mannelijk (bijv. hij, hemzelf, man, jongen, Peter), vrouwelijk (bijv. zij, haarzelf, vrouw, meisje, Petra) en genderneutraal (bijv. persoon). We berustten op de Van Dale (2005) om vast te stellen of we te maken hebben mannelijke, vrouwelijke of 'genderneutrale' beroepsnamen.

Namen als chauffeur, bakker, monteur, voetballer en meervoudsvormen als studenten werden als mannelijk geclassificeerd, omdat Van Dale (2005) chauffeuse, bakkeres, monteuse, voetbalster en studentes als vrouwelijk alternatief voorstelt. Termen als loodgieter, admiraal of exporteur werden ook als mannelijk gerekend, want alhoewel er geen vrouwelijk alternatief beschikbaar is, werd in de woordenboekdefinitie het mannelijke geslacht gespecifieerd door woorden als vakman, hij of koopman. Woorden met vrouwelijke suffixen (bijv. -es, -e, -ster, -in 
en -esse) zoals zangeres, assistente, verkoopster, koningin en secretaresse werden als vrouwelijk gerekend.

We classificeerden een naam als 'genderneutraal' wanneer de Van Dale (2005) geen vrouwelijke variant van de (historisch) mannelijke vorm aangaf. Namen als dokter, tandarts, conciërge, ober, slager, postbode, wethouder, ingenieur, verpleegkundige, computerdeskundige en glazenwasser en vormen als personeel en zeelieden werden op deze manier als 'genderneutraal' geclassificeerd. In Taal vitaal (1998), De sprong (2011) en Taal totaal (2017) worden mannelijke namen (bijv. dominee, ambtenaar, medewerker, monteur en groenteboer) waarvoor vrouwelijke alternatieven bestaan achttien keer gebruikt om expliciet naar zowel mannen als vrouwen of naar geen van beide seksen te verwijzen. Deze gevallen werden daarom eveneens als 'genderneutraal' geclassificeerd.

\subsubsection{De meest frequente vrouwelijke en mannelijke beroepen}

Uit deze analyse blijkt in welke beroepen vrouwen en mannen het meest zichtbaar zijn in de hoofdstukken. We plaatsten de vijf meest frequent genoemde vrouwelijke en mannelijke beroepen per tijdvak in een tabel. Vervolgens onderzochten we of deze behoren tot de tien meest mannelijke (bouw/techniek) of vrouwelijke (verzorgend/administratief) beroepen, met lage tot hoge status, in Nederland als vastgesteld door het CBS (CBS, 2005).

\subsubsection{Mannelijke generieken en male firstness}

Uit deze analyse blijkt of en in welke mate vrouwen worden achtergesteld door deze linguïstische aspecten. Voor ieder hoofdstuk noteerden we het aantal mannelijke generieken, oftewel, het verwijzen naar vrouwen door middel van mannelijke (voor)naamwoorden. Ten tweede analyseerden we male firstness, oftewel het plaatsen van mannen vóór vrouwen in verwijzingen naar beide seksen binnen een zin (zie Introductie voor voorbeelden). Indien aanwezig noteerden we ook vrouwelijke generieken of instanties van female firstness.

\subsubsection{Het subgenre 'dialogen'}

Uit deze analyse blijkt hoeveel vrouwen en mannen spreken in conversaties en over welke thema's. We bepaalden hoeveel dialogen er in ieder hoofdstuk stonden en hoeveel mannen en vrouwen er aan elke dialoog deelnemen. We stelden voor elk dialoog het totale aantal types en tokens vast en berekenden hoeveel types en tokens door mannen en door vrouwen geuit worden in relatieve frequentie. Ook noteerden we met welke thema's mannen en vrouwen in verband worden gebracht en hoe vaak dit gebeurt. We classificeerden thema's naar de categorieën van Lee en Collins (2009). 


\subsubsection{Mannen en vrouwen op afbeeldingen}

Uit deze analyse blijkt op welke manier mannen en vrouwen visueel gepresenteerd worden. Voor ieder hoofdstuk werd het aantal afbeeldingen met mensen vastgesteld. Vervolgens telden we hoeveel mannen en vrouwen hierop werden afgebeeld. We bepaalden hoeveel afbeeldingen pasten binnen drie categorieën van Schmitz (1975): exclusie, onderschikking en degradatie. Er was sprake van exclusie, wanneer er alleen mannen of alleen vrouwen op afbeeldingen voorkwamen. Onderschikking werd geïnterpreteerd als het verschijnen van vrouwen of mannen in gendertypische, lage- of middel-status beroepen. Het beroep op de afbeelding moest dan voorkomen in de CBS-top tien van de meest gendertypische, lage- of middel-status beroepen (CBS, 2005). De CBS-statusclassificatie is gebaseerd op opleidingsniveau. ${ }^{3}$ Er was sprake van degradatie wanneer vrouwen of mannen neerbuigend werden bejegend.

\section{Resultaten}

\subsection{Type-token analyse van beroepsnamen}

Het corpus bevatte opgeteld 505 beroepsnamen. In Figuur 1 zijn de aantallen en percentages voor mannelijke (259; 51,3\%, bijv. chauffeur), vrouwelijke (130; 25,7\% bijv. secretaresse) en 'genderneutrale' (116; 23,0\%, bijv. wethouder) beroepsnamen per tijdvak weergegeven. Wat opvalt, is dat in alle tijdvakken mannelijke beroepsnamen het meest frequent voorkomen. Gemiddeld kwamen per boek meer mannelijke beroepsnamen $(M=17, S E=4)$ dan vrouwelijke $(M=9, S E=2)$ voor. Dit verschil was significant $t(14)=4.589, p<.001, d=.070$. Van de 1689 tokens in het corpus verwezen $912(54,0 \%)$ naar mannelijke; 487 (28,8\%) naar vrouwelijke en $290(17,2 \%)$ naar 'genderneutrale' beroepsnamen. Wegens beperkte ruimte rapporteren we de absolute tokenaantallen per periode niet hier, maar deze zijn beschikbaar via de IRIS-database. ${ }^{4}$ Gemiddeld kwamen per boek meer tokens voor mannelijke $(M=61, S E=8)$ dan vrouwelijke $(M=32, S E=9)$ beroepsnamen voor. Dit verschil was significant $t(14)=4.123, p<.001, d=0.873$. 'Genderneutrale' namen worden vanaf 1990 steeds vaker gebruikt, met de sterkste aanwezigheid in de drie meest recente boeken in het corpus (32,4\% in 2010-2017). In deze boeken is ook het laagste aantal vrouwelijke namen te bespeuren $(14,9 \%)$.

3. Een anonieme beoordelaar wees aan dat men in vervolgstudies de beroepenindex van Sixma en Ultee (1983) kan gebruiken voor de classificatie van beroepsstatus.

4. https://www.iris-database.org/iris/app/home/detail?id=york:935944 


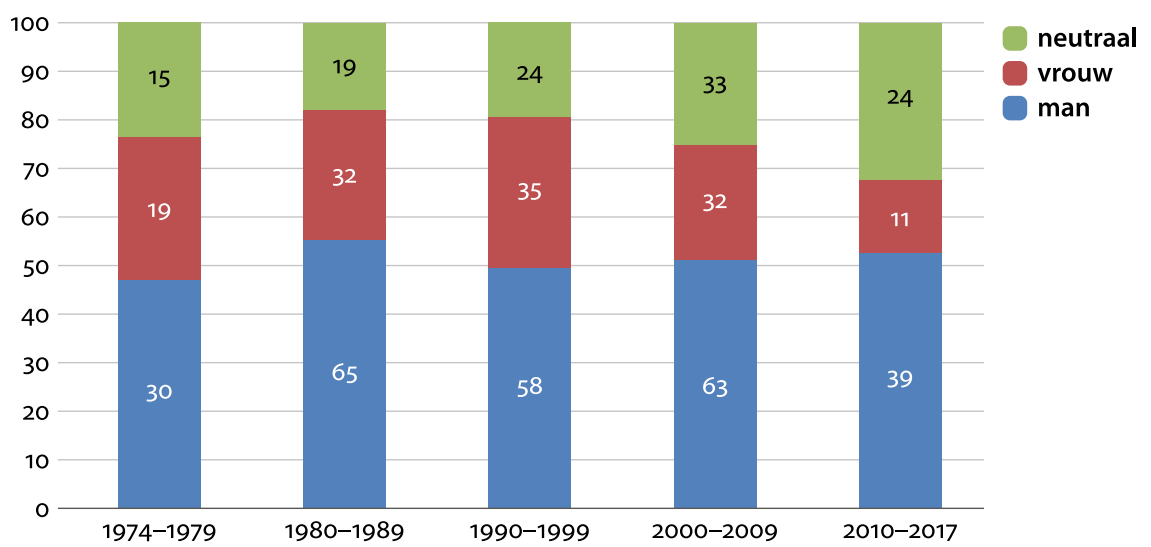

Figuur 1. Frequenties en percentages van mannelijke, vrouwelijke en 'genderneutrale' beroepsnamen per onderzocht tijdvak

Voor de 290 tokens voor de 116 'genderneutrale' beroepsnamen (bijv. wethouder) is het interessant precies vast te stellen hoe vaak deze verwijzen naar mannen (bijv. hij), vrouwen (bijv. zij) of neutrale (bijv. persoon) personen. Resultaten tonen dat $142(49 \%)$ van de tokens verwijzen naar mannen, 54 (18,6\%) naar vrouwen en $94(32,4 \%)$ naar genderneutrale personen. Gemiddeld verwezen per boek meer 'genderneutrale' beroepsnamen naar mannen $(M=9, S E=4)$ dan vrouwen $(M=4, S E=2)$. Dit verschil was niet significant $t(14)=2.027, p=.062, d=.479$. Figuur 2 toont de frequenties en percentages van tokens voor 'genderneutrale' namen per tijdvak. Hierbij is het opvallend dat in de periode 1980-1989 vrouwen überhaupt niet worden beschreven met 'genderneutrale' beroepsnamen, maar dat deze in 2010-2017 in gelijke mate verwijzen naar mannen $(54,6 \%)$ en vrouwen $(45,4 \%)$. Wanneer we de mannelijke dominantie qua types en tokens in aanmerking nemen en daarbij het descriptieve gegeven nemen dat gemiddeld de meeste neutrale beroepsnamen naar mannen verwijzen, blijkt uit deze data dat werkzame mannen aanzienlijk zichtbaarder zijn in NT2-methodes van 1974 tot 2017 dan werkende vrouwen. 


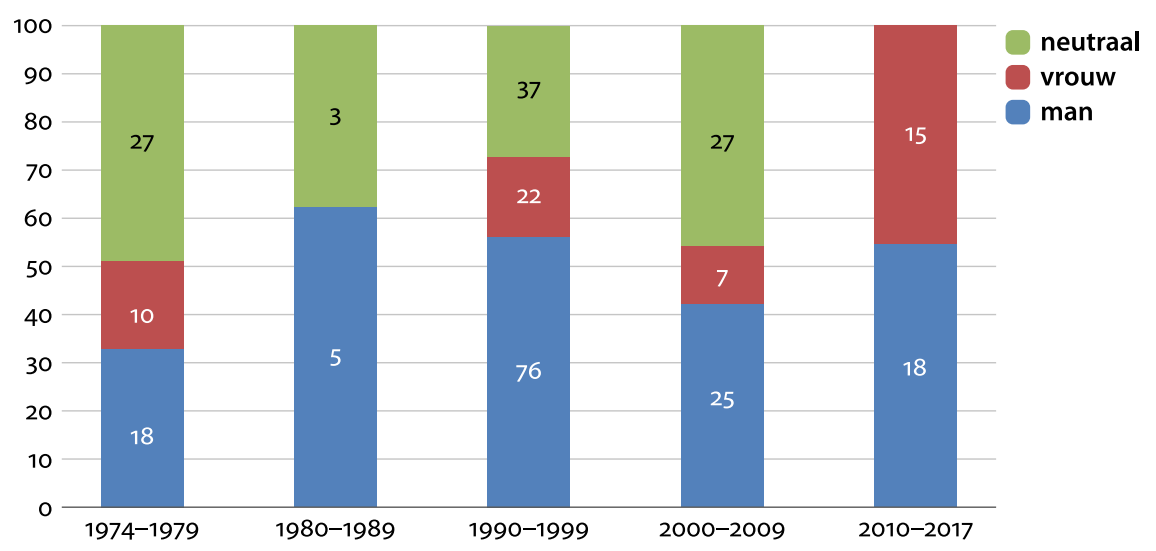

Figuur 2. Frequenties en percentages van mannelijke, vrouwelijke en genderneutrale tokens voor 'genderneutrale' beroepsnamen per onderzocht tijdvak

\subsection{De meest frequente vrouwelijke en mannelijke beroepen}

Tabel 1 laat per tijdvak zien in welke beroepen vrouwen het vaakst worden beschreven. In de kolom 'Totaal' zijn de beroepen weergegeven met de hoogste absolute frequenties in het gehele corpus. Van de 25 meest frequente beroepen (18 types) komen 8 instanties ofwel 3 types (verpleegster, secretaresse, assistente) overeen met een beroep uit de CBS-top tien van de meest vrouwelijke beroepen (CBS, 2005). In Tabel 2 vallen de beroepen typiste, verkoopster, kapster, caissière, intercedente en telefoniste ook in de -volgens het CBS vrouwelijke- categorie 'verzorgend/administratief' te plaatsen; architecte is het enige beroep wat men met de -volgens het CBS mannelijke- categorie 'bouw/techniek' associëren kan. Van de 18 types vallen 11 als beroepen met lage tot middelmatige status te classificeren en twee beroepen kan men classificeren als beroepen met hoge status (koningin, architecte). De beroepen verpleegster (43 instanties) en secretaresse (32 instanties) zijn de meest prototypische beroepen waarin vrouwen worden getoond.

Tabel 1. Per tijdvak de top vijf van de meest frequent genoemde vrouwelijke beroepen

\begin{tabular}{lllllll}
\hline & $\mathbf{1 9 7 4 - 1 9 7 9}$ & $\mathbf{1 9 8 0 - 1 9 8 9}$ & $\mathbf{1 9 9 0 - 1 9 9 9}$ & $\mathbf{2 0 0 0 - 2 0 0 9}$ & $\mathbf{2 0 1 0 - 2 0 1 7}$ & Totaal \\
\hline 1 & Typiste & Verpleegster & Intercedente & Secretaresse & Secretaresse & Verpleegster \\
$\mathbf{2}$ & Verpleegster & Secretaresse & Secretaresse & Serveerster & Lerares & Secretaresse \\
3 & Verkoopster & Koningin & Verpleegster & Stewardess & Intercedente & Verkoopster \\
4 & Kapster & Journaliste & Caissière & Verkoopster & Assistente & Intercedente \\
5 & Telefoniste & Redactrice & Agente & Presentatrice & Architecte & Typiste \\
\hline
\end{tabular}

In Tabel 2 wordt per tijdvak getoond in welke beroepen mannen het vaakst worden beschreven. Van de 25 meest frequente beroepen (19 types) komen 2 
instanties ofwel één type (chauffeur) overeen met een beroep uit de CBS-top tien van de meest mannelijke beroepen (CBS, 2005). Het beroep kapper valt in de categorie 'verzorgend' te plaatsen, maar geen van de beroepen valt in de categorie 'bouw/techniek'. Van de 19 types vallen 17 te classificeren als lage of middelstatusberoepen en twee beroepen als hogere status-beroepen (regisseur, directeur). Het beroep leraar ( 89 instanties) is het meest prototypische beroep waarin mannen worden getoond. Al met al zien we dat vrouwen vaker in typisch vrouwelijke beroepen worden beschreven en dat mannen in gevarieerdere en atypisch mannelijke beroepen worden beschreven.

Tabel 2. Per tijdvak de top vijf van de meest frequent genoemde mannelijke beroepen

\begin{tabular}{lllllll}
\hline & $\mathbf{1 9 7 4 - 1 9 7 9}$ & $\mathbf{1 9 8 0 - 1 9 8 9}$ & $\mathbf{1 9 9 0 - 1 9 9 9}$ & $\mathbf{2 0 0 0 - 2 0 0 9}$ & $\mathbf{2 0 1 0 - 2 0 1 7}$ & Totaal \\
\hline $\mathbf{1}$ & Boer & Student & Leraar & Leraar & Leraar & Leraar \\
$\mathbf{2}$ & Chauffeur & Journalist & Stagiair & Politieagent & Student & Student \\
3 & Directeur & Analist & Conducteur & Adviseur & Manager & Chauffeur \\
4 & Leraar & Leraar & Kapper & Regisseur & Onderzoeker & (Politie)Agent \\
5 & Fotograaf & Groenteboer & Agent & Zanger & Chauffeur & Boer \\
\hline
\end{tabular}

\subsection{Mannelijke generieken en, male firstness}

In het corpus zijn 46 mannelijke generieken te vinden tegenover nul vrouwelijke generieken. Het meest recente boek in het corpus, Taal totaal (2017), bevatte de meeste mannelijke generieken (23), terwijl de oudste drie boeken (1974-1979) geen bevatten. In het corpus waren 144 instanties van male firstness te vinden tegenover 13 instanties van female firstness. We rekenden ook oefeningen waarbij vrouwelijke beroepsnamen van mannelijke moeten worden afgeleid als instanties van male firstness. Taal vitaal (1998) bevatte het hoogste aantal, de helft van het totale aantal, instanties van male firstness (72). Al met al zien we dat vrouwen op de achtergrond worden geplaatst door deze talige constructies, ook in recenter materiaal.

\subsection{Het subgenre 'dialogen'}

Het corpus bevatte 31 dialogen, waaraan 28 vrouwen, 28 mannen en 6 genderneutrale karakters (vaak een genderneutrale interviewer) deelnamen. Opgeteld bevatte het sub corpus met dialogen 1745 types en 3842 tokens. Vijf boeken bevatten geen dialogen, andere boeken bevatten één tot zes dialogen. Het gespreksaandeel in het corpus lag iets hoger voor mannen, die $62,5 \%$ van de types en $56,0 \%$ van de tokens uitten. De frequentie van vrouwelijke (vriend- 
schap, ziekte en uiterlijk) gespreksthema's volgens Lee en Collins (2009) lag voor mannen op 3 en voor vrouwen op 7. De frequentie van mannelijke gespreksthema's (criminaliteit, politiek, nationale identiteit en succes) lag voor vrouwen op 1 en voor mannen op 4 . Effectief spraken vrouwen dus vaker over vrouwelijke dan mannelijke thema's, maar mannen spraken over zowel vrouwelijke als mannelijke thema's.

We vonden twee opvallende patronen in de analyse van gespreksthema's die niet binnen de categorieën van Lee en Collins (2009) pasten. Ten eerste viel op dat vrouwen viermaal werden geassocieerd met het thema 'onvoldoende beroepskwalificaties/geen succes', terwijl dit voor mannen niet voorkwam. Ter illustratie volgt een dialoog, getiteld "Even lachen", uit Niederländisch ohne Mühe (197, p.201):

1. Om kort te gaan u kunt $^{\star}$ niet typen (2), u kent geen stenografie (3) u hebt* nooit boekhouding gedaan*. 2. Van handelscorrespondentie (4) hebt u niet het minste benul. Maar juffrouw, waarvoor meldt u zich dan aan. 3. - Voor de overuren.

Ten tweede viel op dat mannen achtmaal over salaris/financiën praatten, terwijl vrouwen dit thema niet bespraken. Al met al zien we dat vrouwen en mannen ongeveer evenveel aan het woord komen in dialogen, maar dat gespreksthema's onevenredig verdeeld zijn over de groepen. Mannen spreken over zowel typisch mannelijke en typisch vrouwelijke thema's volgens Lee en Collins (2009), terwijl vrouwen vaker werden geassocieerd met typisch vrouwelijke thema's.

\subsection{Mannen en vrouwen op afbeeldingen}

In totaal bevatte ons corpus 255 afbeeldingen met 413 personen, waarvan 191 mannen en 222 vrouwen. Op 51 foto's $(20,0 \%)$ werden vrouwen en mannen samen afgebeeld; op 89 foto's $(34,9 \%)$ werden alléén mannen afgebeeld en op 87 foto's $(34,1 \%)$ alléén vrouwen. Volgens de categorieën van Schmitz (1975) was er op $37,0 \%$ van de foto's sprake van exclusie van vrouwen en op $44,3 \%$ exclusie van mannen. Hier werden alleen mannen of vrouwen of meer mannen dan vrouwen of andersom afgebeeld. Op 5,5\% van de foto's was er sprake van vrouwelijke onderschikking (bijv. een secretaresse met een baas). Op 5,0\% van de foto's viel mannelijke onderschikking te constateren. Degradatie kwam bijna niet voor in het corpus en niet in de meest recente materialen (2010-2017). Slechts één afbeelding kwam in aanmerking voor de categorie vrouwelijke degradatie en twee afbeeldingen voor mannelijke degradatie. In Code Nederlands (1990, p.152), bijvoorbeeld, wordt een conducteur kleinerend bejegend door een reiziger in een striptekening ("Zit u thuis ook met uw schoenen op de bank? - Knipt u thuis ook kaartjes?”). Al met al zien we dat vrouwen en mannen op ongeveer evenredige 
wijze worden afgebeeld, zowel in termen van frequentie als in termen van de categorieën die Schmitz (1975) voorstelde.

\section{Conclusie}

Het doel van deze studie was uit te vinden hoe vrouwen en mannen zijn gerepresenteerd in NT2-tekstboekhoofdstukken over werk uit de afgelopen 50 jaar. We onderzochten dit door vijftien hoofdstukken over beroep en werk uit NT2-boeken van 1974-2017 kwantitatief en kwalitatief te analyseren. De algemene hypothese was dat vrouwen ondergerepresenteerd zijn, maar dat dit minder sterk zichtbaar is in onderwijsmateriaal verschenen in de laatste twintig jaar.

\subsection{Zichtbaarheid van vrouwen in $\mathrm{NT} 2$-onderwijsmateriaal}

Uit de type-token analyses bleek dat mannelijke professionals in leerboeken zichtbaarder zijn dan vrouwen, ook in materiaal uit de laatste twintig jaar. Dit verschil wordt primair veroorzaakt door de dominantie van mannelijke beroepsnamen met grote aantallen tokens die hiernaar verwijzen en doordat 'genderneutrale' beroepsnamen het vaakst naar mannen verwijzen. Deze bevinding sluit onder andere aan bij resultaten van Bengoechea en Simón (2010), die tot eenzelfde conclusie kwamen voor leerboeken Spaans. De bevindingen leveren geen ondersteuning voor de bewering van Sunderland (2014), die stelde dat boeken gepubliceerd in de afgelopen twintig jaar steeds vaker gendergelijkheid tonen. Het is aannemelijk dat de genderongelijkheid in NT2-methodes te maken heeft met het ontbreken van officiële richtlijnen voor het gebruik van gender en beroepsnamen in het Nederlands. Met betrekking tot 'genderneutrale' beroepsnamen, zagen we dat deze recentelijk (2010-2017) wel evenredig vaak naar vrouwen en mannen verwijzen. Deze trend sluit aan bij De Backer en De Cuypere (2012), die vonden dat 'neutrale' naamwoorden steeds vaker naar zowel vrouwen als mannen verwijzen, volgens sprekers van het Belgisch-Nederlands. Volgens Vervecken e.a., (2013) en Vervecken e.a. (2015) betekent dit echter niet dat vrouwen net zo vaak als succesvolle professionals worden gezien als mannen. Uit hun studies bleek dat vrouwelijke (naast mannelijke) beroepsnamen de voorkeur hebben voor een evenredige perceptie van succes van mannen en vrouwen.

We bekeken ook in welke beroepen vrouwen en mannen werden beschreven. Hieruit kwam naar voren dat vrouwen veelvuldig in de, volgens het CBS, vrouwelijke beroepscategorie 'verzorgend/administratief' worden geplaatst. Mannen worden niet in de, volgens het CBS, mannelijke beroepscategorie 'bouw/techniek' beschreven en worden in gevarieerdere categorieën dan vrouwen beschreven. 
Deze grotere variatie in beroepsmogelijkheden voor mannen dan vrouwen sluit aan bij eerder gevonden contrasten in leerboeken Engels (Sunderland, 2015). Bengoechea en Simón (2010, p. 201) vonden eveneens dat leraar het meest frequente beroep voor mannen was en dat verpleegster en secretaresse de meest frequente beroepen voor vrouwen waren in 23 leerboeken Spaans gepubliceerd voor 2004. Vrouwen en mannen werden even vaak in lage en middel-statusberoepen afgebeeld en zelden in hogestatusberoepen. Deze bevinding verschilt van vroegere bevindingen in leerboeken Frans en Engels die toonden dat vrouwen vaker dan mannen beroepen met lage status bezetten (Schmitz, 1975; Jiménez Catalán \& Ojeda Alba, 2001). Schrijfsters, schrijvers, uitgeefsters en uitgevers van NT2-methodes kiezen mogelijk voor lage- of middelstatusberoepen, omdat die bij een breder publiek aansluiten. Hierdoor bleven potentiële gendercontrasten in beroepen met hoge status uit.

Resultaten toonden dat vrouwen worden achtergesteld door mannelijke generieken en veelvuldiger door male firstness. Dit sluit aan bij eerdere bevindingen in leerboeken Engels (Sunderland, 2015). Mannelijke generieken komen het vaakst voor in het meest recente boek uit het corpus, Taal totaal (2017). Dit ondersteunt het idee dat vrouwelijke onzichtbaarheid ook geldt voor recent materiaal. ${ }^{5}$ Wanneer we dialogen in hoofdstukken bekijken, vinden we dat het gespreksaandeel voor mannen iets hoger lag dan dat voor vrouwen. Deze data ondersteunen vrouwelijke onderrepresentatie dus in geringe mate. Wel zien we genderongelijkheid in de toebedeling van gespreksthema's. Net als in de frequentieanalyse van beroepsnamen (Sectie 4.2) zien we dat mannen over gevarieerdere, zowel typisch vrouwelijke als mannelijke, thema's praten, terwijl vrouwen vaker over typisch vrouwelijke thema's spreken in termen van Lee en Collins (2009). Het was opvallend dat vrouwen met onvoldoende beroepskwalificaties in verband werden gebracht, en nooit over salaris praatten, terwijl mannen dit wel deden, maar nooit met onvoldoende kwalificaties werden geassocieerd. Net als in dialogen, worden vrouwen en mannen ongeveer even vaak afgebeeld in het corpus. Degradatie kwam zelden voor net als onderschikking. Hier zien we dus een discrepantie tussen woord en beeld, omdat uit de beroepsnamenanalyse (Sectie 4.1 en 4.2) een mannelijke dominantie bleek.

Terugkerend naar de algemene hypothese kunnen we het volgende concluderen. Wanneer we dialogen en afbeeldingen in NT2-methodes bekijken, zien we dat vrouwen niet ondergerepresenteerd zijn. Vrouwen en mannen zijn ongeveer even vaak aan het woord en worden ongeveer even vaak afgebeeld. Qua thematiek

5. Een anonieme beoordelaar wees aan dat men zich kan afvragen in hoeverre de tand des tijds in leermiddelen wordt weerspiegeld als wel persoonlijke opvattingen en voorkeuren van een individuele schrijver, schrijfster, uitgeefster of uitgever. 
in gesprekken en rollen waarin mannen en vrouwen worden afgebeeld zijn er wel genderonevenredigheden te bespeuren, die ertoe leiden dat vooral vrouwen niet in de breedte van mogelijke gespreksthema's of rollen worden getoond. Wanneer we naar mannelijke generieken en male firstness kijken, vinden we ondersteuning voor het idee dat vrouwen op de achtergrond worden geplaatst. Met name male firstness komt regelmatig voor, ook in NT2-methodes uit de laatste twintig jaar. Onzichtbaarheid van vrouwen wordt echter het meest duidelijk door het veelvuldige gebruik van mannelijke beroepsnamen en 'genderneutrale' namen die naar mannen verwijzen in contrast met het lage aantal vrouwelijke beroepsnamen. Ook worden werkzame vrouwen voornamelijk in administratieve en verzorgende beroepen beschreven, terwijl mannen in gevarieerdere categorieën worden beschreven. Deze situatie is eerder verslechterd dan verbeterd in materiaal gepubliceerd in de laatste twintig jaar.

\subsection{Vervolgonderzoek en pedagogische implicaties}

In termen van vervolgonderzoek valt ten minste één belangrijk onderzoeksgebied aan te wijzen, dat is perceptie van vrouwelijke, mannelijke en 'genderneutrale' beroepsnamen door NT2-studenten. Het is interessant te onderzoeken of perceptieresultaten met (Belgisch )Nederlands moedertaalsprekers (Vervecken e.a., 2013; Vervecken e.a., 2015) te repliceren zijn met NT2-leerders. Men zou voorafgaand een mannelijke (alleen mannelijke beroepsnamen en mannelijke generieken), vrouwelijke (alleen vrouwelijke beroepsnamen) en genderfaire (vrouwelijke en mannelijke beroepsnamen in paarvorm) instructie kunnen geven en perceptie van succes meten. In plaats van genderperceptie van enkele woorden zou men hierbij genderperceptie in discours, zoals in tekstboekteksten, dialogen en oefeningen uit NT2-methodes, experimenteel kunnen onderzoeken. Indien de resultaten gerepliceerd kunnen worden en ongelijke genderrepresentaties in leermateriaal ongelijke perceptie van succes van werkende vrouwen en mannen in de hand werken, bestaat er een sterk argument om NT2-onderwijsmateriaal aan te passen in termen van gendergelijkheid.

Voor onderwijspractici voor wie het argument voor gendergelijkheid ook zonder verdere experimentele ondersteuning sterk weegt, vallen aanbevelingen vast te stellen. Ten eerste kan de zichtbaarheid van vrouwen in huidig materiaal worden vergroot door frequenter gebruik van vrouwelijke beroepsnamen en eventueel het frequenter verwijzen naar vrouwen door middel van 'genderneutrale' beroepsnamen. Ten tweede kunnen vrouwen in meer gevarieerde rollen worden beschreven dan in de afgelopen 50 jaar het geval was. Vrouwen kunnen ook als werkzaam in typisch mannelijke domeinen als bouw en techniek en mannen in typisch vrouwelijke domeinen als administratie en verzorging worden 
beschreven. Ten derde kunnen uitgeefsters en uitgevers hun materiaal controleren op mannelijke generieken en male firstness. In een oefening over vrouwelijke en mannelijke beroepsnamen, kunnen mannelijke namen bijvoorbeeld ook van de vrouwelijke worden afgeleid, in plaats van andersom. Ten vierde is het vanuit een gendergelijkheidsperspectief aan te bevelen om gespreksthema's in dialogen in NT2-boeken evenredig te verdelen over mannelijke en vrouwelijke sprekers.

Zelfs als uitgeefsters en uitgevers hun materiaal niet willen herzien, zijn er voor NT2-docentes en -docenten die gendergelijkheid nastreven strategieën voor de omgang met genderongelijke representaties in onderwijsmateriaal. Sunderland e.a. (2001) vonden in een verkennende studie dat docentes en docenten Engels traditionele genderrepresentaties weerspraken door rollen om te draaien of (humoristisch) te overdrijven of dat ze representaties bevestigden door deze te ondersteunen of negeren. In termen van vervolgonderzoek is het interessant de validiteit van het model van Sunderland e.a. (2001) te onderzoeken door te documenteren in welke mate $\mathrm{NT}_{2}$-docentes en -docenten traditionele genderrollen anno 2019 bevestigen of weerspreken (Koster \& Litosseliti, in voorbereiding).

Terugkerend naar NT2-onderwijsmateriaal, kan vervolgonderzoek vanuit verdere foci materiaal analyseren. Sunderland (2015) noemt onder andere nog de analyse van actieve (bijv. rijden, lopen, fietsen) en passieve (bijv. zitten, wachten, slapen) werkwoorden waarmee vrouwen en mannen worden beschreven. Giaschi (2000) en Kuipers e.a. (2017) stellen een diepgaandere, kwalitatieve analyse van afbeeldingen voor aan de hand van vragen (bijv. Wie is actief en passief? Waar is de kijkrichting? Hoe wordt het lichaam afgebeeld?). Verder kan vervolgonderzoek de representatie van sociale categorieën die interageren met gender, zoals seksualiteit, etniciteit en klasse onder de loep nemen (Sunderland, 2015). Sunderland (2015) stelt bijvoorbeeld dat leerboeken Engels het kerngezin, bestaande uit een heteroseksuele, witte moeder en vader met twee kinderen uit de middenklasse, steeds weer centraal stelt, terwijl 'andere' families (in termen van seksualiteit, etniciteit, klasse et cetera) zelden voorkomen. Familie is bovendien een interessant domein voor onderzoek, omdat gebaseerd op voorgaand onderzoek (Ott, 2015; Bag \& Bayyurt, 2015) te verwachten valt dat in dit domein juist mannen minder zichtbaar zijn dan vrouwen. Nieuw onderzoek naar gender en seksualiteit in de beschrijving van familie in NT2-methodes zou kunnen helpen om gradaties van heteronormativiteit in leermaterialen bloot te leggen en belangrijke kennis opleveren die ten bate komt van inclusief talenonderwijs. 


\section{Dankwoord}

Deze studie is tot stand gekomen binnen het college Taal, gender en NT2-onderwijsmateriaal aan de Universiteit Münster in het wintersemester van 2017-18. Dit paper bevat bijdrages van: Laure, Rani, Jana, Lukas, Katherina, Mara, Tabea, Apolline, Elisabeth, Lena, Febe, Philip en Anna. We bedanken Anna Pot, Gunther de Vogelaer, Esther Ruigendijk en twee anonieme beoordelaars voor het becommentariëren van eerdere versies van dit paper.

\section{Literatuurlijst}

Anthony, L. (2018). AntConc (Version 3.5.6) [Computer Software]. Tokyo, Japan: Waseda University. Available from http://www.laurenceanthony.net/software

Bag, E., \& Bayyurt, Y. (2015). Gender representations in textbooks in Turkey. In S. Mills, \& A. Mustapha (Eds.), Gender representation in learning materials. International perspectives (pp. 64-85). New York/London: Routledge.

Bengoechea, M., \& Simón, J. (2010). Gender identity in words for professional titles in textbooks. In R. Jiménez Catalán (Ed.), Gender perspectives on vocabulary in foreign and second languages (pp. 188-211). UK: Palgrave McMillan. https://doi.org/10.1057/9780230274938_9

Bolle, J. (2017). NS vervangt "dames en heren" door "reizigers". NRC. Opgevraagd 21 februari 2018, van https://www.nrc.nl/nieuws/2017/o7/28/ns-vervangt-dames-en-heren-doorreizigers-a1568177

Bossers, B., Kuiken, F., Vermeer, A., Andringa, S., Bakker, R., \& Hosea, I. (2015). Handboek Nederlands als tweede taal in het volwassenenonderwijs (Tweede druk. Tweede oplage 2017). Bussum: Coutinho.

Butler, J. (1990). Performative acts and gender constitution: An essay in phenomenology and feminist theory. In S.-E. Case (Ed.), Performing feminism: Feminist critical theory and theatre (pp. 270-82). Baltimore, Md: Johns Hopkinds University Press.

Centraal Bureau voor de Statistiek (2005). Een top tien van mannen- en vrouwenberoepen. Opgevraagd 21 februari 2018, van https://www.cbs.nl/nl-nl/nieuws/2005/47/een-toptienvan-mannen-en-vrouwenberoepen

Centraal Bureau voor de Statistiek (2010). Vrouwen vaak verkoopster, mannen vaak vrachtwagenchauffeur. Opgevraagd 21 februari 2018, van https://www.cbs.nl/nl-nl/nieuws /2010/47/vrouwen-vaak-verkoopster-mannen-vaak-vrachtwagenchauffeur (opgevraagd, 21 februari 2018)

Centraal Bureau voor de Statistiek (2017). Groei arbeidsdeelname afgevlakt. Opgevraagd 21 februari 2018, van https://www.cbs.nl/nl-nl/nieuws/2017/37/groei-arbeidsdeelnameafgevlakt

De Backer, M., \& De Cuypere, L. (2012). The interpretation of masculine personal nouns in German and Dutch: A comparative experimental study. Language Sciences, 34(3), 253-268. https://doi.org/10.1016/j.langsci.2011.10.001

De Caluwe, J., \& Van Santen, A. (2001). Gezocht: Functiebenamingen $(\mathrm{m} / \mathrm{v})$. Wegwijzer voor vorming en gebruik van Nederlandse functiebenamingen. The Hague: SDU Uitgevers. 
Gerritsen, M. (2002). Towards a more gender-fair usage in Netherlands Dutch. In M. Hellinger, \& H. Bussmann, (Eds), Gender across languages, Volume II (pp. 82-108). Amsterdam: John Benjamins. https://doi.org/10.1075/impact.10.1oger

Giaschi, P. (2000). Gender positioning in education: A critical image analysis of ESL texts. TESL Canada Journal, 18(1), 32-46. https://doi.org/10.18806/tesl.v18i1.898

Gouvias, D., \& Alexopoulos, C. (2018). Sexist stereotypes in the language textbooks of the Greek primary school: A multidimensional approach. Gender and Education, 30(5), 642-662. https://doi.org/10.1080/09540253.2016.1237620

Jiménez Catalán, R., \& Ojeda Alba, J. (2001). Sex/Gender in the illustrations of an ESL dictionary. In A. Antón Pacheco (Eds.), Estudios de la mujer en el ámbito de los países de habla inglesa (pp. 67-96). Madrid: Universidad Complutense.

Jones, M., Kitetu, C., \& Sunderland, J. (1997). Discourse roles, gender and language textbook dialogues: Who learns what from John and Sally? Gender and Education, 9(4), 469-490. https://doi.org/10.1080/09540259721204

Koster, D., \& Litosseliti, L. (in voorbereiding). Wanted: gender conscious teachers - An exploration of teachers' handlings with gendered texts in Dutch foreign language education.

Kuipers, G., Van der Laan, E. , \& Arfini, E. (2017). Gender models: Changing representations and intersecting roles in Dutch and Italian fashion magazines, 1982-2011. Journal of Gender Studies, 26(6), 632-648. https://doi.org/10.1080/09589236.2016.1155435

Lakoff, R. (1973). Language and woman's place. Language in Society, 2(1), 45-80. https://doi.org/10.1017/So047404500000051

Lee, J., \& Collins, P. (2009). Construction of gender: A comparison of Australian and Hong Kong English text books. Journal of Gender Studies, 19(2), 121-137. https://doi.org/10.1080/09589231003695856

Lee, J., \& Collins, P. (2015). Gender representation in Hong Kong primary English-language textbooks: A corpus study. In S. Mills, \& A. Mustapha, (Eds.), Gender representation in learning materials. International perspectives (pp. 37-51). New York/London: Routledge.

Menard-Warwick, J., Mori, M., \& Williams, S. (2017). Language and gender in educational contexts. In S. Ehrlich, M. Meyerhoff, \& J. Holmes (Eds.), The handbook of language, gender and sexuality (pp. 471-490). Oxford: Wiley Blackwell.

Mustapha, A., \& Mills, S. (2015). Gender representation in learning materials in an international context. In S. Mills, \& A. Mustapha (Eds.), Gender representation in learning materials. International perspectives (pp. 9-18). New York/London: Routledge.

Mustapha, A. (2015). Gender positioning through visual images in English-Language textbooks in Nigeria. In S. Mills, \& A. Mustapha (Eds.), Gender representation in learning materials. International perspectives (pp. 150-163). New York/London: Routledge. https://doi.org/10.4324/9781315764092

Ott, C. (2015). Innocent maths? Gender representations in German maths books. In S. Mills, \& A. Mustapha (Eds.), Gender representation in learning materials. International perspectives (pp. 52-63). New York/London: Routledge.

Pawelczyk, J., \& Pakula, L. (2015). Constructing gender and sexuality in the EFL classroom in Poland: Textbook construction and classroom negotiation? In S. Mills, \& A. Mustapha (Eds.), Gender representation in learning materials. International perspectives (pp. 193-212). New York/London: Routledge.

Peters, L. (2016). Geen man of vrouw? Dan ben je voortaan een "hen”. De Correspondent. Opgevraagd, 21 februari 2018, van https://decorrespondent.nl/4748/geen-man-of-vrouwdan-ben-je-voortaan-een-hen/1050864703020-d399a42e 
Risager, K. (2018). Representations of the world in language textbooks. Bristol: Multilingual Matters. https://doi.org/10.21832/RISAGE9559

Romein-Verschoor, A. (1975). Over taal en seks, seksisme en emancipatie. De Gids, 138(1/2), 3-36.

Schmitz, B. (1975). Sexism in French language textbooks. In R.C. Lafayette (Ed.), The cultural revolution in foreign language teaching. (pp. 119-130). Skokie, IL: National Textbook Co.

Sixma, H., \& Ultee, W. (1983). Een beroepsprestigeschaal voor Nederland in de jaren tachtig. Mens en Maatschappij, 4(58), 360-382.

Stahlberg, D., Sczesny, S., \& Braun, F. (2001). Name your favourite musician. Effects of masculine generics and their alternatives in German. Journal of Language and Social Psychology, 2o(4), 464-469. https://doi.org/10.1177/0261927X01020004004

Stromquist, N., Lee, M., \& Brock-Utne, B. (1998). The explicit and the hidden school. In N. Stromquist, \& K. Monksman (Eds.), Women in the third world: An encyclopedia of contemporary issues (pp. 397-407). New York: Garland Publishing.

Summers, D. (1992). Dictionary of English language and culture. Harlowe/Essex: Longman.

Sunderland, J. (1994). Introduction. In J. Sunderland (Ed.), Exploring gender: Questions and implications for English language education. London: Prentice Hall.

Sunderland, J., Cowley, M., Fauziah, A., Leontzakou, C., \& Shattuck, J. (2001). From bias "in the text" to "teacher talk around the text". An exploration of teacher discourse and gendered foreign language textbook texts. Linguistics and Education, 11(3), 251-286. https://doi.org/10.1016/So898-5898(00)00034-6

Sunderland, J. (2010). Theorizing gender perspectives in foreign and second language learning. In R.M. Jiménez Catalán (Ed.), Gender perspectives on vocabulary in foreign and second languages (pp. 1-19). UK: Palgrave McMillan. https://doi.org/10.1057/9780230274938_1

Sunderland, J. (2014). Gender representation in language textbooks: Moving on. Plenary lecture, Young Linguists' Meeting, Poznan.

Sunderland, J. (2015). Gender (representation) in foreign language textbooks: Avoiding pitfalls and moving on. In S. Mills, \& A. Mustapha (Eds.), Gender representation in learning materials. International perspectives (pp. 19-34). New York/London: Routledge.

Van Dale Groot Woordenboek van de Nederlandse taal (14th ed.) (2005). Utrecht: Van Dale Lexicografie.

Van Leeuwen, T. (2008). Discourse and practice: New tools for critical discourse analysis. Oxford: Oxford University Press. https://doi.org/10.1093/acprof:oso/9780195323306.001.0001

Vermeulen, M. (2018). "Herr Professorin" of: Hoe maak je taal echt sekseneutraal? De Volkskrant: Sir Edmund, 29, 42-44.

Vervecken, D., Hannover, B., \& Wolter, I. (2013). Changing (s)expectations: How gender-fair job descriptions impact children's perceptions and interest regarding traditionally male occupations. Journal of Vocational Behavior, 82(3), 208-220. https://doi.org/10.1016/j.jvb.2013.01.008

Vervecken, D., Gygax, P., Gabriel, U., Guillod, M., \& Hannover, B. (2015). Warm-hearted businessmen, competitive housewives? Effects of gender-fair language on adolescents' perceptions of occupations. Frontiers in Psychology, 6(1437).

https://doi.org/10.3389/fpsyg.2015.01437 


\section{Appendix. Overzicht van de geanalyseerde NT2-boeken}

\begin{tabular}{|c|c|c|c|}
\hline Titel & Jaar & $\begin{array}{l}\text { Onderzochte } \\
\text { pagina's }\end{array}$ & Referentie \\
\hline Actief Nederlands & 1976 & $67-72$ & $\begin{array}{l}\text { Van Passel, F. (1976). Actief Nederlands } 1 . \\
\text { Antwerpen: De Sikkel. }\end{array}$ \\
\hline Actief Nederlands & 1976 & $134-139$ & $\begin{array}{l}\text { Van Passel, F. (1976). Actief Nederlands } 2 . \\
\text { Antwerpen: De Sikkel. }\end{array}$ \\
\hline Code Nederlands & 1990 & $148-156$ & $\begin{array}{l}\text { Kuiken, F., \& Van Kalsbeek, A. (1990). Code } \\
\text { Nederlands. Basisleergang Nederlands voor volwassen } \\
\text { anderstaligen 1. Tekstboek. Amsterdam: Meulenhoff } \\
\text { Educatief. }\end{array}$ \\
\hline Code Nederlands & 1990 & $152-159$ & $\begin{array}{l}\text { Kuiken, F., \& Van Kalsbeek, A. (1990). Code } \\
\text { Nederlands. Basisleergang Nederlands voor volwassen } \\
\text { anderstaligen 1. Oefenboek. Amsterdam: Meulenhoff } \\
\text { Educatief. }\end{array}$ \\
\hline Contact! & 2009 & $272-279$ & $\begin{array}{l}\text { De Leeuw, E., De Groot, F., Cornax, A., \& Roël, P. } \\
\text { (2009). Contact! Nederlands voor anderstaligen. } \\
\text { Tekstboek. Amsterdam/Antwerpen: Intertaal. }\end{array}$ \\
\hline Contact! & 2009 & $221-229$ & $\begin{array}{l}\text { De Leeuw, E., De Groot, F., Cornax, A., \& Roël, P. } \\
\text { (2009). Contact! Nederlands voor anderstaligen. } \\
\text { Werkboek. Amsterdam/Antwerpen: Intertaal. }\end{array}$ \\
\hline Delftse methode & 1985 & $75-93$ & $\begin{array}{l}\text { Montens, F., \& Sciarone, A. (1985). Nederlands voor } \\
\text { buitenlanders. De Delftse methode. Amsterdam: } \\
\text { Boom. }\end{array}$ \\
\hline De sprong & 2011 & $8-27$ & $\begin{array}{l}\text { Beersmans, M., \& Tersteeg, W. (2011). De sprong. } \\
\text { Van NT2-niveau A2 naar B1. Amsterdam: Boom. }\end{array}$ \\
\hline Ijsbreker & 1994 & $125-135$ & $\begin{array}{l}\text { Liemberg, E., Huizinga, M., \& Jansen, F. (1994). } \\
\text { Ijsbreker. Basisleergang Nederlands voor volwassen } \\
\text { anderstaligen 2. Tekstboek. Amsterdam: Meulenhoff } \\
\text { Educatief. }\end{array}$ \\
\hline Ijsbreker & 1994 & $242-263$ & $\begin{array}{l}\text { Liemberg, E., Huizinga, M., \& Jansen, F. (1994). } \\
\text { Ijsbreker. Basisleergang Nederlands voor volwassen } \\
\text { anderstaligen 2. Oefenboek. Amsterdam: Meulenhoff } \\
\text { Educatief. }\end{array}$ \\
\hline $\begin{array}{l}\text { Levend } \\
\text { Nederlands }\end{array}$ & 1984 & $23-30$ & $\begin{array}{l}\text { Trim, J., Matter, J. (1984). Levend Nederlands. Een } \\
\text { cursus Nederlands voor buitenlanders. Cambridge: } \\
\text { Cambridge University Press. }\end{array}$ \\
\hline $\begin{array}{l}\text { Nederlands. } \\
\text { Taalcursus voor } \\
\text { buitenlanders }\end{array}$ & 1988 & $\begin{array}{l}111-118 \\
149-156\end{array}$ & $\begin{array}{l}\text { Stegeman, J. (1988). Nederlands. Taalcursus voor } \\
\text { buitenlanders. Deel 1. Leiden: Martinus Nijhoff. }\end{array}$ \\
\hline $\begin{array}{l}\text { Nederlands in } \\
\text { actie }\end{array}$ & 2012 & $16-48$ & $\begin{array}{l}\text { De Boer, B., Van der Kamp, M., Lijmbach, B. (2012). } \\
\text { Nederlands in actie. Methode NT2 voor hoogopgeleide } \\
\text { anderstaligen. Bussum: Coutinho. }\end{array}$ \\
\hline
\end{tabular}




\begin{tabular}{|c|c|c|c|}
\hline Titel & Jaar & $\begin{array}{l}\text { Onderzochte } \\
\text { pagina's }\end{array}$ & Referentie \\
\hline $\begin{array}{l}\text { Nederlands voor } \\
\text { anderstaligen in } \\
\text { het voortgezet } \\
\text { onderwijs }\end{array}$ & 1978 & $35-44$ & $\begin{array}{l}\text { Van Egmond-Van Helten, H.M. (1978). Nederlands } \\
\text { voor anderstaligen in het voortgezet onderwijs } 4 . \\
\text { Leerlingenboek. Groningen: Wolters-Noordhoff. }\end{array}$ \\
\hline $\begin{array}{l}\text { Niederländisch } \\
\text { ohne Mühe }\end{array}$ & 1974 & $\begin{array}{l}173-175 \\
195-203 \\
253-256 \\
277-280\end{array}$ & $\begin{array}{l}\text { Cherel, A. (1974). Niederländisch ohne Mühe. } \\
\text { Amsterdam: Assimil. }\end{array}$ \\
\hline Taal totaal nieuw & 2017 & $30-42$ & $\begin{array}{l}\text { Simons, G. (2017). Taal totaal nieuw. Nederlands } \\
\text { voor gevorderden. Werkboek. Amsterdam/Antwerpen: } \\
\text { Intertaal. }\end{array}$ \\
\hline Taal totaal nieuw & 2017 & $26-35$ & $\begin{array}{l}\text { Van Keulen, S. (2017). Taal totaal nieuw. Nederlands } \\
\text { voor gevorderden. Tekstboek. Amsterdam/Antwerpen: } \\
\text { Intertaal. }\end{array}$ \\
\hline Taal vitaal & 1998 & $56-63$ & $\begin{array}{l}\text { Schneider-Broekmans, J. (1998). Taal vitaal. } \\
\text { Niederländisch für Anfänger. Arbeitsbuch. Ismaning: } \\
\text { Max Hueber Verlag. }\end{array}$ \\
\hline Taal vitaal & 1998 & $58-65$ & $\begin{array}{l}\text { Schneider-Broekmans, J. (1998). Taal vitaal. } \\
\text { Niederländisch für Anfänger. Lehrbuch. Ismaning: } \\
\text { Max Hueber Verlag. }\end{array}$ \\
\hline Totaal & 2007 & $89-99$ & $\begin{array}{l}\text { Van den Broek, A. (2007). Totaal. Basiscursus } \\
\text { Nederlands voor anderstaligen. 's-Hertogenbosch: } \\
\text { Efficace. }\end{array}$ \\
\hline Welkom! & 2009 & $74-83$ & $\begin{array}{l}\text { Abitzsch, D., Sudhoff, S. (2009). Welkom! } \\
\text { Niederländisch für Anfänger. Lehrbuch mit Audio- } \\
\text { CD. Stuttgart: Klett. }\end{array}$ \\
\hline
\end{tabular}

\section{Correspondentieadres}

Dietha Koster

Westfälische Wilhelms-Universität Münster

Institut für Niederländische Philologie

Alter Steinweg 6/7

Münster, 48145

Germany

dikoster@uni-muenster.de

(iD) https://orcid.org/oooo-0003-1596-8818 


\section{Co-auteur informatie}

Chiara Iding

Westfälische Wilhelms-Universität Münster

Institut für Niederländische Philologie

c_idino1@uni-muenster.de

\section{Publicatiegeschiedenis}

Date received: 23 July 2018

Date accepted: 7 December 2018

Published online: 13 August 2019 